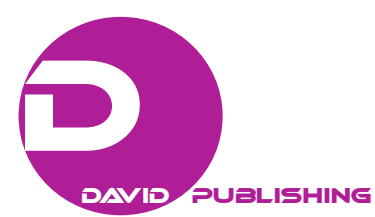

\title{
Factors Determining Health Expenditure in the Asian and the OECD Countries
}

\author{
Paitoon Kraipornsak \\ Chulalongkorn University, Bangkok, Thailand
}

\begin{abstract}
It is widely recognized that developed countries have been spending more than developing countries on health care. Objective of the study is to examine determinants of health expenditure and what factors influence it. Fifteen Asian countries and 30 OECD countries were chosen to explore the difference of their health expenditure structures. Model of health expenditure per person was estimated to be dependent on market demand, market supply, and other exogenous factors. A model with country specific and time effects of health expenditure was used and estimated. The study found a negative but insignificant relationship between price and health expenditure and a positive and significant relationship between GDP and health expenditure. Urban population density as proxy of urbanization was found to induce the health expenditure in the OECD. Out-of-pocket payment was also found to induce health expenditure for both the Asian and the OECD countries. A net effect of improvement in the health status or a lower mortality rate and a higher life expectancy caused an increase in the health expenditure among the Asian countries studied but decreased health expenditure in the OECD countries. In terms of income elasticity, it was found to be smaller than one in both groups of the countries. Since the income has changed faster than the other factors, the net effect of changes of all factors over period of time will cause rising in health care expenditure. Finally, the model indicated that both the Asian and OECD countries will continue to have a rising health expenditure per person over a period of time.
\end{abstract}

Keywords: health expenditure, rising trend of health expenditure, Asian countries, OECD countries, country fixed effect, time fixed effect, income elasticity, necessary service

\section{Introduction}

Health care services have been playing an increasing role in almost every country in the world. An evidence is the rising records of health expenditure per Gross Domestic Product (GDP). A significant increase in health expenditure across regions in the world can be showed in Table 1. This suggests that a significant part of resources in these economies have been geared towards the health sector (Table 1).

Table 2 shows the trends of health expenditure per person among different groups of countries. These differences in the rising trend of expenditure can be explained by various factors. It is observable that total health expenditure per person seems to grow faster and reach the fastest growth at the upper middle income level before its growth is slowing down. The smaller rates of growth for the riches countries, however,

Paitoon Kraipornsak, Ph.D., associate professor of Economics, Faculty of Economics, Chulalongkorn University, Bangkok, Thailand.

Correspondence concerning this article should be addressed to Paitoon Kraipornsak, Faculty of Economics, Chulalongkorn University, Pathumwan, Bangkok 10330, Thailand. 
do not necessarily mean the size of the increases in total health expenditure is smaller than these of the poorer ones.

These two tables indicate that two different countries have different behavior of spending on healthcare. In addition, the rich countries spend more than the poor country on health services. Objective of this study is to examine determinants of health expenditure and what factors influence it. In order to compare health expenditure comparatively, Asian countries and OECD countries were chosen to explore the difference.

Table 1

Total Health Expenditure (\% GDP)

\begin{tabular}{|c|c|c|c|c|c|c|}
\hline & 1995 & 2000 & 2005 & 2010 & 2013 & \% pa. \\
\hline Least developed countries & 4.31 & 3.82 & 4.61 & 5.22 & 4.97 & 4.59 \\
\hline Lower middle income & 3.82 & 3.99 & 4.29 & 4.11 & 4.25 & 4.09 \\
\hline Middle income & 4.69 & 4.99 & 5.31 & 5.56 & 5.81 & 5.27 \\
\hline Upper middle income & 5.01 & 5.33 & 5.66 & 6.04 & 6.27 & 5.66 \\
\hline High income: OECD & 9.51 & 10.10 & 11.31 & 12.50 & 12.63 & 11.21 \\
\hline OECD members & 9.41 & 9.92 & 11.10 & 12.24 & 12.34 & 11.00 \\
\hline High income: Non OECD & 5.41 & 5.60 & 4.68 & 5.54 & 5.37 & 5.32 \\
\hline World & 8.68 & 9.11 & 9.89 & 10.13 & 9.97 & 9.56 \\
\hline
\end{tabular}

Source: World Bank.

Table 2

Health Expenditure per Person (US\$2010 Price, PPP)

\begin{tabular}{lllllll}
\hline & 1995 & 2000 & 2005 & 2010 & 2013 & \% pa. \\
\hline Least developed countries & 36.69 & 42.53 & 64.52 & 94.20 & 109.99 & $\mathbf{7 . 1 \%}$ \\
Lower middle income & 80.00 & 99.85 & 151.46 & 189.27 & 234.43 & $\mathbf{7 . 1 \%}$ \\
Middle income & 124.04 & 171.17 & 261.46 & 392.12 & 498.26 & $\mathbf{9 . 3 \%}$ \\
Upper middle income & 171.06 & 249.15 & 386.51 & 631.94 & 817.08 & $\mathbf{1 0 . 7 \%}$ \\
High income: OECD & $2,138.10$ & $2,743.84$ & $3,777.99$ & $4,786.77$ & $5,236.40$ & $\mathbf{5 . 4 \%}$ \\
OECD members & $1,886.39$ & $2,418.60$ & $3,318.22$ & $4,199.06$ & $4,579.00$ & $\mathbf{5 . 4 \%}$ \\
High income: Non-OECD & 469.91 & 613.54 & 817.63 & $1,403.65$ & $1,589.09$ & $\mathbf{7 . 9 \%}$ \\
World & 480.97 & 605.83 & 828.96 & $1,086.18$ & $1,223.35$ & $\mathbf{5 . 7 \%}$ \\
\hline
\end{tabular}

Source: World Bank.

In the next section, review of related literatures will be provided. Research methods will then follow in Section 3. Section 4 presents discussion of results of the study. Conclusion will be followed next in Section 5.

\section{Literature Review}

There is an interesting information on health expenditure for the United States. The USA Fact Sheet (2016) reported that retail prescription spending on drugs grew at the fastest rate along other types of services of personal care at a rate of 12.2 percent in 2014. This rapid growth was in the category of spending on new medications especially specialty drugs such as hepatitis $\mathrm{C}$ and brand-name drugs. Other personal health care spending that grew at a fast pace included a resurgence in growth of non-price factors such as the use and intensity of services and hospital care, spending for physicians and clinical services, and spending for medical equipment and products. When considering this by the type of sponsor, it was found that households and the federal government had the two largest shares of health care spending (about 28 percent each). 
Although the United States has the highest level of health expenditure, its growth has been decelerating recently. Lorenzoni, Belloni, and Sassi (2014) examined trends of health care expenditure among OECD countries and found that the higher prices of the health sector could explain the difference between the United States and five other high health spending OECD countries. Hence, the dynamics of price may largely explain the decelerating health expenditure growth.

A decelerating growth rate of health expenditure is also found in Canada. Canada health spending per person is in the top 25 percent of the world after Denmark, France, Australia, and the United Kingdom while the United States shows the highest health spending per person. Canada's total health spending growth is slower than the inflation and population growth rate together. When taken into consideration by types of health spending, the three largest health spending are hospital (29.5 percent), drugs (15.7 percent), and physician services (15.5 percent). Even though these three spending types are found to have increased; their growth rates have slowed a little in recent years (Canadian Institute for Health Information, 2015).

A number of research have been conducted for determinants of health expenditure and many studies found income to be the most important factor determining health care expenditure. Newhouse (1977) assessed income elasticity using cross-country data during 1970s. The result showed that the aggregate income elasticity was 1.35 that is greater than 1 and it was significant. A few studies also found that the aggregate income elasticity was greater than one. Gerdtham, Sogaard, Andersson, and Jonsson (1992) estimated a function of health care expenditure to be dependent on income (GDP), institutional factors, and socio-demographic factors for 20 OECD countries over the period of 1960-1987. This study found that income elasticity was larger than one.

Hitiris and Posnett (1992) however found income elasticity of health care close to one by controlling unobserved heterogeneity by introduced country-specific effects. Baltagi and Moscone (2010), on the contrary, found an income elasticity to be smaller than one. Baltagi and Moscone used a panel of 20 OECD countries over the period of 1971-2004 to estimate the long run relationship between health expenditure and income. They estimated the average of the slope coefficients by using Common Correlated Effects Pooled estimator including individual specific fixed effect and time dummies to capture the heterogeneity. Non-Staionarity of variables was checked before estimating income elasticity as a set of regressors and unobserved common factors was controlled. Their finding suggested the health care to be necessary service with a small elasticity.

Atella and Marini (2006) examined relationship between income and health expenditure using 20 OECD countries during the time period of 1960-2000. A main question in the research was whether health care can be a luxury service. The model followed a standard demand function and explained that per capita health care expenditure was a function of per capita income (measured at PPP) and relative price of health care (ratio of health care price index to the GDP deflator). Other exogenous factors in the model included dependency rate, share of public expenditure on GDP, and linear deterministic time trend as being a proxy for technological change. Public and private health expenditures were differentiated in the model. It was found that differences in income elasticity were greater than one and varied from 1.115 for private health care expenditure in non-National Health Services to 1.265 for public health care expenditure for National Health Service countries. Income elasticity of both private and public health care expenditures was found almost always higher in National Health Service countries than non-National Health Service countries. It indicated a significant role of different country-specific health care system. This implies that income elasticity is sensitive to structure of health system. 
Ke, Saksena, and Holly (2011) used dynamic models to estimate factors with total health expenditure for 143 countries over the period of 1995 to 2008. Fixed effect model was used in the estimation. By taking government health expenditure, the study found that income was inelastic and varied from 0.75 to 0.95 in the fixed effect model. In particular, for the static model, income elasticity was found greater than one for low income countries, but it was smaller than one for the other income groups. By taking total health expenditure, in the static model income elasticity was less than one for low- and upper-middle income countries: it was around one in low and high income countries. In any cases, the income elasticity was much lower in the dynamic model. The growth of health expenditure was also dependent on levels of economic development. In general, they found that health expenditure did not grow faster than GDP.

Murray, Govindaraj, and Musgrove (1994) studied national health expenditures for all countries of the world. Per capita income, government and private consumption as percent of GDP, years of schooling, per cent of urban population, regional dummy variables, and health status were included in their public health expenditure model. Infant mortality rate and life expectancy at birth were two indicators as proxies of the health status. The study found a close relation between public health expenditure and income together with the other factors. However, the study did not find causal relation between health expenditure and health status. They explored and found some unknown mixture of varying effectiveness of health expenditure as well as different health status among countries.

Health care costs can be a part of the determinants of rising health care expenditure. Health technology could reduce total health expenditure when it improves efficiency of health services. On the contrary, advanced and expensive technology can also be a major cost-increasing factor of health services when it is too excessive or inessential.

Studies to estimate the effect of technology have been done by at least three different approaches: the residual approach, the proxy approach, and case study analysis. The residual approach is based on the assumption that technology is measured by any changes that are not caused by any quantifiable factors. The proxy approach uses an existing indicator assuming the changes follow technological improvement. Case studies examine the effect of a specific technology on its cost on health treatment. Dybezak and Przywara (2010) studied health expenditure, but concentrated on the impact of technology. They assessed the impact of medical technology on health expenditure by constructing an econometric model of health care expenditure. A deterministic trend was used to assess the impact of technology on health care spending. However, this trend could include any other non-demographic factors. Using a pooled fixed effect regression, they found that the trend coefficient was positive and significant confirming its effect on health expenditure.

A panel data of 25 OECD countries over the period of 1985-2006 was used to estimate health expenditure determinants (Hosoya, 2014). Real health expenditure per head was regressed on two major variables, real per capita GDP, and proportion of the population aged 65 and over on total population. Other controlling and explanatory variables were population density and the socio-economic variables. The model takes time variable to be a proxy for technological change. The study used fixed effect model and found income elasticity less than one implying that health care is a necessary service. The important result found when the study re-estimated the model under alternative period of 1990-2006 and 1997-2006 to check robustness, the study concluded that health care service is a necessary service. A new different finding showed that aging population became a significant factor determining health expenditure during the shorter period of 1997-2006. This finding was therefore claimed by the author to be a signal of a critical transition in health care environment. Technological change was also found to be a key factor associated to rising health costs. 
Health insurance and advanced technology can also encourage medication and prescription. The USA experiences many of these arguments such as unnecessary drug prescription, individual risks of proposed and expensive treatment from possible side effects, tendency to prescribe antibiotics, and potentially nonexistent condition for drug, including tricky treatment in complicated cases (Bloomberg Business News, July 28, 2009). Those mentioning factors can increase the overall cost of health care.

Urbanization can lead to expensive services due to overcrowded health care facilities causing dis-economies of scale. The payment scheme in the health care market can also influence the difference in health expenditure. Out-of-pocket is one of the health payment schemes in financing health care. Statistics of its payment as a percentage of total health expenditure clearly shows that it was relatively small in the advanced countries compared to most Asian countries. In 2013, the percentages are 5.4, 7.4, 9.3, 10.7, 10.8, 11.8, 14.4, 15.8, 16.3, 16.8, 18.0, 18.5, 19.1, and 19.9 for the Netherlands, France, the UK, New Zealand, Luxemburg, the US, Japan, Austria, Sweden, Ireland, Italy, Finland, Australia, and Belgium, respectively. The out-of-pocket expenditure is as large as 68.2, 60.2, 59.7, 58.2, 56.8, 56.7, 54.9, 49.4, 46.5, 46.2, 45.8, 40.0, 36.6, 36.1, 33.9, 25.4, and 11.3 in the Asian countries of Myanmar, Bangladesh, Cambodia, India, Singapore, the Philippines, Pakistan, Vietnam, Sri Lanka, Nepal, Indonesia, the Lao PDR, South Korea, Malaysia, China, Bhutan, and Thailand, respectively (World Health Organization). The large amount of out-of-pocket payments in Asia is probably explained by the fact that there is less social protection for health in those Asian countries.

\section{Research Methods}

\section{Scope of the Study}

The study examined determinants of health expenditure per person in macro-perspective for 15 Asian countries excluding Japan, as it is on a far different stage of development compared to the others. The study also compared the result of the estimation with that of the 30 OECD countries. The 15 Asian countries consist of Bangladesh, Bhutan, Brunei Darussalam, Cambodia, China, India, Indonesia, Korea, Rep, Lao PDR, Malaysia, Mongolia, Nepal, Philippines, Thailand, and Vietnam. The 30 OECD countries in the study were Australia, Austria, Belgium, Chile, Canada, Czech Republic, Denmark, Estonia, Finland, France, Germany, Greece, Iceland, Ireland, Israel, Italy, Japan, Korea, Rep, Netherlands, New Zealand, Norway, Poland, Portugal, Slovak Republic, Slovenia, Spain, Sweden, Switzerland, United Kingdom, and the United States. By taking the same structure of the model, the estimated health expenditure could be used to compare sizes of income effect and its elasticity of both country groups including investigation of some other determining factors. Selected countries included in the study were based on the availability of the data for all related variables used in the model. The data used in the estimation were drawn from the World Bank (data.worldbank.org) and the World Health Organization (http://www.who.int/gho/health_financing/en/).

\section{The Model}

In general, health expenditure per person is dependent on market demand, market supply, and other exogenous factors. Conceptually, rising health expenditure can be considered in detail as two components. Rising costs of health services and an increasing demand for health services can explain this increasing trend.

A model of health expenditure per person was constructed and analyzed. The expenditure is dependent on market demand and supply including important exogenous factors based on the standard economic theory. The econometric model of health expenditure is shown below in Equation (1). 


$$
\begin{gathered}
H E_{i t}=\beta_{0}+\beta_{1} H P_{i t}+\beta_{2} \ln \left(Y_{i t}\right)+\beta_{3} U R B_{i t}+\beta_{4} O U T_{i t} \\
\beta_{5} M O R_{i t}+\beta_{6} L I F_{i t}+\vartheta_{i}+\tau_{t}+\varepsilon_{i t}
\end{gathered}
$$

where

HE is total health expenditure per person measured in constant 2011 prices (dollar) based on purchasing power parity (PPP).

HP is health care prices of which data are not available. A proxy variable was calculated by dividing health expenditure per person measured in current prices by health expenditure per person measured in constant 2011 prices (dollar).

$\mathrm{Y}$ is GDP measured in constant 2011 prices (dollar) based on PPP.

URB is urban population measured in \% of total population.

OUT is out-of-pocket health expenditure measured in \% of total expenditure on health.

MOR is mortality rate measured in per 1,000 infant live births.

LIF is life expectancy at birth measured in years.

$\vartheta_{i}$ and $\tau_{\mathrm{t}}$ are the country effect and the time effect.

$\mathrm{i}=$ countries in the sample (details of the countries included in the study are shown in Appendix)

$\mathrm{t}=$ year of the observation, from 1995 to 2013

As previously mentioned, health expenditure per person (HE) is based on PPP and in constant prices to represent the real expenditure on health to render their incomes internationally comparable. It depends negatively on health care price (HP) and positively on real income (Y).

In this study, health expenditure per person also depends on four other exogenous factors namely urban population (URB), out-of-pocket health payment (OUT), mortality rate (MOR), and life expectancy rate (LIF). Urbanization (urban population: URB) is expected to be a proxy of the scale effect or economies/diseconomies of scale. A high urbanization rate may raise health expenditure because of overcrowded health care facilities or excessive demand for health care services or vice versa. Out-of-pocket schemes (OUT) may also affect the health care system and therefore it is interesting to examine whether it can significantly help to reduce or increase the expenditure on health care. Mortality rate (MOR) and life expectancy at birth (LIF) are two important health status or health outcome variables that can be related to health expenditure. While a high mortality rate may increase the health expenditure, a longer life expectancy may also cause people to end up spending more on their health care. Nevertheless, a longer life expectancy could indicate a healthier life and therefore smaller health care spending per person.

The income variable was measured in logarithmic form. Hence, the marginal effect of health expenditure is interpreted with respect to a one percentage change in income. The other variables are in their forms of proportion or ratio except for health expenditure per person and life expectancy at birth.

\section{Research Results and Discussion}

The health expenditure model was estimated for the two groups of countries using a panel of estimation method. The first estimation features the 15 Asian countries, listed in the appendix; while the second estimation uses 30 OECD countries. The regression model takes into account the country specific and time effects, and other factors that account for different socio-economic and political backgrounds of the countries in the sample. Hausman test was used to examine whether the model should be estimated by the fixed or random effects. 
Under the null hypothesis of preferring the random effect model, the test for the first estimation using the 15 Asian countries found a significant statistic $\left(\chi_{6}^{2}=101.7025\right)$, and therefore the fixed country and time effects for the Asian health expenditure model were estimated and adopted. The estimated model is shown in Equation (2).

$$
\begin{aligned}
& H E_{i t}=-19138.97-11.1192 H P_{i t}+484.2922 \ln \left(Y_{i t}\right)-1.4033 U R B_{i t} \\
& \text { (t) } \quad(-6.8725)^{* *}(-0.9396) \quad(5.2880)^{* *} \quad(-0.7777) \\
& +2.8864 \text { OUT }_{i t}+30.4155 \text { MOR }_{i t}+119.6707 L I F \\
& \text { (t) } \quad(3.8005)^{* *} \quad(11.9676)^{* *} \quad(11.8851)^{* *}
\end{aligned}
$$

Adjusted $\mathrm{R}^{2}=0.9301, \mathrm{~F}$-statistic $=104.0420[\mathrm{P}=0.0000]$, Sum squared resid $=5188897$

$* *=$ at 0.01 level of significance. $*=$ at 0.05 level of significance

As expected, the price effect was found to be negatively related to health expenditure per person but it was statistically insignificant. This insignificant effect of the price on the expenditure implies that the price of health care was not an important factor determining health expenditure. Patients require physicians for their health services no matter how much the price is as long as they can pay or can find money to pay it. It may also imply that health service is not completely responded by its prices due to being under control of the government or heavily subsidized.

The marginal income effect was found to be positively related to health expenditure per person and significant. A percentage point increase in the income of people could raise health expenditure per person by 484 dollars on average for the Asian countries in this study. Considering income elasticity, the coefficient must be divided by value of health expenditure per head. In 2013, the calculated income elasticity of health care of the Asian countries was 0.81 which indicated a necessary service.

Urbanization was found to be statistically insignificant, meaning that it could not significantly reduce health expenditure per person. It can be observed later that the urbanization rate in the Asian countries is lower than those in advanced or industrialized countries used in this study.

In addition, an increase in the out-of-pocket increases health expenditure per person. This payment scheme was actually found to significantly increase health expenditure for both the Asian and OECD countries.

Improvement in health status in term of a smaller mortality rate was found to reduce health expenditure per person while an increase in life expectancy at birth increased health expenditure per person. The combination of these two effects of smaller mortality and increased life expectancy is the net effect of the improvement of the health status. A positive or negative net effect depending on which size of each effect is relatively larger. The result of simulation found that the net effect of the improvement of the health status, disregarding the other factors, has caused an increase in health expenditure per person by an average amount of US\$ 8,913 to US\$ 9,860 (PPP based) among the 15 Asian countries in the study.

The country fixed effect was found to be between the maximum of 1,167 for Brunei Darussalam and the minimum of $-3,309$ for China (Table 3). The average time effect was found to be -5.7390 throughout the time period in the study. While the country specific effects were different among countries, the time effect showed a small decrease of health expenditure on average over the time period in the study.

To examine the health expenditures of these Asian countries in more detail, the estimated model was compared with one for same advanced countries (OECD). Hence, the model of health expenditure per person was estimated for the 30 OECD countries. The fixed effect model was used and estimated, suggested by the significant test statistic of the Hausman test $\left(\chi_{6}^{2}=84.5846\right)$. The result of estimation for the OECD countries 
is shown in Equation (3).

$$
\begin{aligned}
& H E_{i t}=80.5767-0.4630 H P_{i t}+387.5659 \ln \left(Y_{i t}\right)+42.1619 U R B_{i t} \\
& (t) \quad(0.0221)(-0.7967) \quad(1.8521) * \quad(13.6115) * * \\
& +9.5339 O U T_{i t}+195.3394 M O R_{i t}-154.9341 L I F \\
& (3.8471)^{* *} \quad(19.3473)^{* *} \quad(-4.7403)^{* *}
\end{aligned}
$$

Adjusted $\mathrm{R}^{2}=0.9520$, F-statistic $=213.0505[\mathrm{P}=0.0000]$, Sum squared resid $=48820559.0$

$* *=$ at 0.01 level of significant. * = at 0.05 level of significant

The results of the estimations for the two regions were generally found to be consistent. Health care prices could not reduce health expenditure on a statistical significant level. An increase in income could raise health expenditure significantly. However the sizes of both effects for the OECD countries were found to be smaller than those for the Asian countries. In terms of income elasticity in 2013 the calculated income elasticity of health care of the OECD countries was 0.11 which also indicated a necessary service.

Interestingly, two major differences were found in the results of these two regions. While the urbanization or urban population ratio was found to negatively affect health expenditure for the Asian but for a statistically insignificant level, it was positively and statistically significant related to health expenditure for the OECD countries. The second difference was the negative and significant effect of life expectancy on health expenditure in the OECD countries, while it was also found with a statistically significant but positive effect on health expenditure for the Asian countries.

The urban population ratio had a positive and a statistically significant effect on health expenditure in the OECD implying that crowded populations in cities could cause health care expenditure per person to be higher or more expensive. The average of urban population rate was higher for the OECD countries (76.56 over the time period of the study) compared to the rate of the Asian sample (44.54 over the time period of the study). This finding implies that the significant higher density of the population in the urban areas in the OECD countries may explain the significant impact of the urbanization factor on rising health expenditure.

While the existence of the fixed effect confirms the countries' specific effect, the time effect could also be considered as an effect of health care technology on health expenditure. From the estimation, it was found that the time effect was small and decreasing over the time period from 1995 to 2013 for the Asian countries and that it was relatively large and increasing for the OECD sample over the same period of time (Table 3). This implies that the advanced technology could cause higher health expenditure per person in the OECD countries over the period of time in the study. This induced health expenditure per head of technology might also explain the higher quality of health care demanded by people of the OECD countries.

A similar pattern found for all countries in the study is out-of-pocket payments. It has a statistically significant and positive effect on health expenditure. However, the size of the impact for the OECD sample was about three times as large as that for the Asian countries. Therefore, the out-of-pocket payment scheme increases health expenditure in both groups of countries but its impact is larger for the advanced economies.

Regarding the improvement in the health status, for the OECD countries, a lower mortality rate by one death per 1,000 infant live births did decrease health expenditure per person by US\$ 195.3. Likewise, a longer life expectancy at birth by one year reduced health expenditure per person by US\$ 154.9. Improvement in both health status indicators is therefore undoubtedly causing a decrease in health expenditure per person. From the 
calculation, it was found that the improvement in both health status indicators has helped to reduce health expenditure per person by an average amount of US\$ 9,706 to US\$ 12,089 (PPP based) among the 30 OECD countries.

Table 3

Country Specific Effect (CSE) and Time Effect (TE)

\begin{tabular}{|c|c|c|c|c|c|c|c|}
\hline Asian & CSE & & TE & OECD & CSE & & TE \\
\hline Bangladesh & -2055.34 & 1995 & 25.65826 & Australia & -128.962 & 1995 & -1691.19 \\
\hline Bhutan & 880.9466 & 1996 & 50.76923 & Austria & 1707.218 & 1996 & -1497.33 \\
\hline Brunei Darussalam & 1166.764 & 1997 & 38.28435 & Belgium & -332.897 & 1997 & -1345.06 \\
\hline Cambodia & -1036.04 & 1998 & 57.77963 & Chilli & -2869.21 & 1998 & -1197.63 \\
\hline China & -3308.59 & 1999 & 28.69656 & Canada & 364.2171 & 1999 & -1036.41 \\
\hline India & -3178.65 & 2000 & -16.5613 & Czech, Rep. & -1216.71 & 2000 & -849.245 \\
\hline Indonesia & -2479.06 & 2001 & -1.01794 & Denmark & 551.8688 & 2001 & -628.692 \\
\hline Korea, Rep. & -1263.04 & 2002 & -4.02772 & Estonia & -1685.78 & 2002 & -428.809 \\
\hline Lao, PDR. & -996.788 & 2003 & -3.07244 & Finland & 278.4513 & 2003 & -254.504 \\
\hline Malaysia & -1211.54 & 2004 & -22.6506 & France & 410.9793 & 2004 & -34.3448 \\
\hline Mongolia & 475.9303 & 2005 & -46.0413 & Germany & 385.2666 & 2005 & 156.1453 \\
\hline Nepal & -867.106 & 2006 & -52.1548 & Greece & -495.441 & 2006 & 410.4891 \\
\hline Philipines & -1513.53 & 2007 & -42.7643 & Iceland & 1990.654 & 2007 & 616.2693 \\
\hline Thailand & -1740.63 & 2008 & -39.4214 & Ireland & 1179.158 & 2008 & 893.6302 \\
\hline Vietnam & -2018.03 & 2009 & 0.074739 & Israel & -892.072 & 2009 & 1141.079 \\
\hline$\overline{M a x}$ & 1166.764 & 2010 & -8.53853 & Italy & 4.066867 & 2010 & 1216.526 \\
\hline \multirow[t]{16}{*}{ Min } & -3308.59 & 2011 & -32.0753 & Japan & -435.269 & 2011 & 1409.147 \\
\hline & & 2012 & -26.4814 & Korea & -2098.27 & 2012 & 1497.603 \\
\hline & & 2013 & -15.4967 & Netherland & 833.6512 & 2013 & 1622.323 \\
\hline & & Average & -5.73899 & New Zealand & -323.811 & Average & -0.00004 \\
\hline & & & & Norway & 2122.845 & & \\
\hline & & & & Poland & -2341.39 & & \\
\hline & & & & Portugal & 232.9793 & & \\
\hline & & & & Slovakia & -1443.21 & & \\
\hline & & & & Slovania & 1258.472 & & \\
\hline & & & & Spain & -705.922 & & \\
\hline & & & & Sweden & 756.5383 & & \\
\hline & & & & Switzerland & 2066.733 & & \\
\hline & & & & UK & -817.602 & & \\
\hline & & & & USA & 1773.545 & & \\
\hline & & & & Max & 2122.845 & & \\
\hline & & & & Min & -2869.21 & & \\
\hline
\end{tabular}

Source: Author's calculation.

A projective conclusion is that health expenditure per person for both the Asian and the OECD samples will continue to rise over a period of time. Although the income elasticity was found to be smaller than one, 
however impact of income was found to be larger than the other factors and hence finally increased heath care expenditure per head. From the estimation results, a merely one percent increase in income a year can increase health expenditure per person by US\$ 387.5 for the OECD sample and by US\$ 484.3 for the Asian sample. The other factors have a much smaller incremental impact on health expenditure. Apart from the smaller impacts of those other-than-income factors, they have been changing on a much slower pace compared to changes in income. Therefore, health expenditure will keep rising for both the OECD and the Asian countries as having been experienced.

\section{Conclusion}

The study analyzed health expenditure in 15 Asian countries. It was also compared to 30 OECD countries in order to investigate any differences. Health expenditure is dependent on market demand, market supply, and other exogenous factors. A health expenditure model with a country specific and time effects was estimated for both groups of countries. The study found a negative but statistically insignificant relationship between the price of health services and its expenditures for both the Asian and the OECD samples. However the study found a significant positive income effect on health expenditure. Both the estimated price and income effects of the OECD countries were smaller than the Asian countries. Urbanization or urban population density was found to insignificantly reduce health expenditure per person for the Asian countries as they are relatively less dense compared to the industrialized countries. The urban population variable was found to induce health expenditure for the OECD economies. Out-of-pocket payment induced total health expenditure in both group of countries and its impact was about three times higher for the OECD economies than for the Asian economies.

Country specific factors were very different from countries. Health technology proxied by the deterministic time trend was however found to cause a decreasing trend in health expenditure in the Asian sample while it caused an increasing trend on health expenditure in the OECD regression.

The net effect of the improvement of the health status caused increase in health expenditure per person by an average amount of US\$ 8,913 to US\$ 9,860 (PPP based) among the Asian countries. Nevertheless, the net improvement of the health status helped to reduce expenditure per person by about an average amount of US\$ 9,706 to US\$12,089 (PPP based) among the 30 OECD countries. Finally, the findings indicate a continued rising health expenditure per person in both the Asian and the OECD economies over a future period of time. The most influential factor among all is the income factor, it has had by far the largest impact and the fastest change.

\section{References}

Atella, V., \& Marini, G. (2006). Is health care expenditure really a luxury good? Re-assessment and new evidence based on OECD data. Retrieved from http://ssrn.com/abstract=383004

Baltagi, B. H., \& Moscone, F. (2010). Health care expenditure and income in the OECD reconsidered: Evidence from panel data. Center for Policy Research, 46. Retrieved from http://surface.syr.edu/cpr/46

Bloomberg Business News. (2016). Retrieved from http://www.bloomberg.com/bw/stories/2009-07-28/health-care-in-crisis-overmedicating-americabusinessweek-business-new s-stock-market-and-financial-advice

Canadian Institute for Health Information. (2015). National health expenditure trends, 1975 to 2015. Retrieved from www.chi.ca/nhex

Dybezak, K., \& Przywara, B. (2010). The role of technology in health care expenditure in the EU. Economic Papers. Directorate-General for Economic and Financial Affairs. European Commission. 
Gerdtham, U. G., Sogaard, J., Andersson, F., \& Jonsson, B. (1992). An econometric analysis of health care expenditure: A cross-section study of the OECD countries. Journal of Health Economics, 11, 63-84.

Hitiris, T., \& Posnett, J. (1992). The determinants and effects of health expenditure in developed countries. Journal of Health Economics, 11, 173-181.

Hosoya, K. (2014). Determinants of health expenditures: Stylized facts and a new signal. Modern Economy, 5, 1171-1180. Retrieved from http://dx.doi.org/10.4236/me.2014.513109

Ke, X., Saksena, P., \& Holly, A. (2011). The determinants of health expenditure: A country-level panel data analysis. World Health Organization Working Paper of the Results for Development Institute (R4D). Retrieved from http://www.resultsfordevelopment.org

Lorenzoni, L., Belloni, A., \& Sassi, F. (2014). Health-care expenditure and health policy in the USA versus other high-spending OECD countries. The Lancet, 384, 83-92.

Murray, C. J. L., Govindaraj, R., \& Musgrove, P. (1994). National health expenditures: A global analysis. Bulletin of the World Health Organization, 72, 623-637.

Newhouse, J. P. (1977). Medical care expenditure: A cross-national survey. Journal of Human Resources, 12, 115-125.

USA Fact $\quad$ Sheet. $\quad$ (2016). Retrieved from http://www.cms.govresearch-statistics-data-and-systemsstatistics-trends-and-reportsnationalhealthexpenddatadownloadshighl ights.pdf 